\title{
The Practice of Exclusive Breastfeeding and Its Sociodemographic Determinants amongst Nursing Mothers at a Tertiary Health Care Institution in South East, Nigeria
}

\author{
Henry N. Chineke1, Anthony C. Iwu2 ${ }^{2}$, Kevin C. Diwe3, Chukwuma B. Duru33, Kenechi A. Uwakwe ${ }^{3}$, \\ Eyitayo E. Emmanuel ${ }^{4}$, Uche R. Oluoha², Ugochukwu C. Madubueze ${ }^{5}$, Emmanuel U. Ndukwu$^{2}$, \\ Ikechi Ohale ${ }^{2}$
}

\author{
${ }^{1}$ Department of Family Medicine Imo State University Teaching Hospital, Orlu, Nigeria \\ ${ }^{2}$ Department of Community Medicine, Imo State University Teaching Hospital, Orlu, Nigeria \\ ${ }^{3}$ Department of Community Medicine, Imo State University, Owerri, Nigeria \\ ${ }^{4}$ Department of Epidemiology and Community Health, Ekiti State University, Ado Ekiti, Nigeria \\ ${ }^{5}$ Department of Community Medicine, Federal Teaching Hospital, Abakaliki, Nigeria \\ Email: *iwuchinedu@yahoo.com
}

How to cite this paper: Chineke, H.N., Iwu, A.C., Diwe, K.C., Duru, C.B., Uwakwe, K.A., Emmanuel, E.E., Oluoha, U.R., Madubueze, U.C., Ndukwu, E.U. and Ohale, I. (2017) The Practice of Exclusive Breastfeeding and Its Sociodemographic Determinants amongst Nursing Mothers at a Tertiary Health Care Institution in South East, Nigeria. Open Journal of Preventive Medicine, 7, 63-73.

https://doi.org/10.4236/ojpm.2017.74006

Received: March 29, 2017

Accepted: April 27, 2017

Published: April 30, 2017

Copyright (c) 2017 by authors and Scientific Research Publishing Inc. This work is licensed under the Creative Commons Attribution International License (CC BY 4.0).

http://creativecommons.org/licenses/by/4.0/

\begin{abstract}
Background: Breastfeeding is a natural and critical act that provides nutrients and energy for the infant and young child; and through a public health intervention such as exclusive breastfeeding, it improves the survival rates of the infant. Objective: To determine the breastfeeding practices and the sociodemographic determinants of exclusive breastfeeding amongst nursing mothers present at the Imo state university teaching hospital Orlu. Methods: A cross sectional analytical study design was used that included all nursing mothers present within a 4 week study period. Data was collected using a structured questionnaire. Descriptive analyses were done with frequencies and summary statistics. Chi square statistics were computed to determine significant associations and binary logistic regression was used to determine sociodemographic predictors of exclusive breastfeeding practice. $\mathrm{P}$ value was set at 0.05 significant level. Results: While most of the respondents were aware of exclusive breastfeeding (92.5\%), only $24 \%$ of the respondents were practicing exclusive breastfeeding. Work and school activities, and the feeling that breast milk was insufficient for the needs of the baby were the reasons for not practicing exclusive breastfeeding for a majority of the respondents (56.6\%). Furthermore, $61 \%$ of those that were practicing non-exclusive breast feeding gave a cereal or infant formula in addition to the breast milk for 3 to 6 months. It was further revealed that there were statistically significant relationships between breastfeeding practice and maternal age $(p=0.003)$, level of maternal education $(p=$
\end{abstract}


$0.005)$ and maternal occupation $(\mathrm{p}=0.006)$. Conclusion: Understanding and taking into cognizance the sociodemographic characteristics will enable the design, and adequate delivery of appropriate and effective strategies that improve exclusive breastfeeding practice.

\section{Keywords}

Exclusive Breastfeeding, Sociodemographic Determinants, Nigeria

\section{Introduction}

Breastfeeding is a natural and critical act that provides optimally, the energy and nutrients required to satisfy all the needs of the child during the first half of infancy and subsequently providing, up to half or more and one third of the child's nutritional and energy needs during the second half of infancy and the second year of life respectively [1].

Exclusive breastfeeding is a public health intervention and one of the most significant strategies for improving infant survival rates. In order to achieve optimal growth and overall wellbeing of the child, the World Health Organization as a consequence of evidenced based findings, has recommended that, infants within one hour of life should be initiated and exclusively breastfed for six months after which, complementary foods should be introduced as breastfeeding continues for up to two or more years [2] [3].

There are increased concerns globally and regionally about the low and in some cases, declining rates of breastfeeding. In Geneva 2016, the United Nations human rights experts advocated that, countries need to stop the inappropriate marketing of breast milk substitutes and at the same time, emphasize and promote breastfeeding as a human right, with the intention of protecting and supporting both mother and child [4]. Notwithstanding, there appears to be a current increase in the number of infants 0 - 6 months being exclusively breastfed globally (46\%) when compared with the period from 2007 to 2014, where only about $36 \%$ was reported to be exclusively breastfed [5].

However, while Eastern and Southern Africa had the highest rates of exclusive breastfeeding, West and Central Africa had the lowest rates with Nigeria having one of the lowest and declining rates in the African continent from $28 \%$ in 1999 to $17 \%$ in 2013. This is in spite of the fact that, almost all children in Nigeria (98\%) have been breastfed at some time or the other [6] [7].

Breastfeeding is of immense benefit to both mother and child with the potential of preventing about 0.8 and 0.02 million annual deaths in children less than 5 years and from breast cancer respectively. While breast milk enhances neurological development and protects the child from diseases like diarrhoea, pneumonia and malnutrition, breastfeeding promotes the health of the mother by improving child birth spacing and reducing the risk of diseases such type 2 diabetes, ovarian and breast cancer; and it also plays an important role in increas- 
ing the household income and improving food security [1] [8]. More so, early initiation and practice of exclusive breastfeeding has been reported to reduce neonatal mortality by up to $22 \%$ and infant mortality by $13 \%$ respectively [9] [10].

In 2012, WHO member states endorsed and committed to support implementation and monitoring of the "Comprehensive implementation plan on maternal, infant and young child nutrition" with one of the six targets being, to increase to at least $50 \%$ the rate of exclusive breastfeeding for the first 6 months by 2025 [5].

In order to achieve this target for the beneficial interest of both mother and child, breast feeding practices have to be supported by addressing the multifactorial determinants not only through law and policy but also through interventions that take into cognizance the sociodemographic factors that may influence the practice of breastfeeding; because, when appropriate and effective interventions are adequately delivered, breastfeeding practices rapidly improves [11]. It is in line with this, that this study aims to determine the sociodemographic determinants of the practice of exclusive breastfeeding among nursing mothers.

\section{Methodology}

\subsection{Study Area}

The study was conducted in Imo State University Teaching Hospital (IMSUTH) situated in Orlu Local Government Area (LGA) of Imo State in South Eastern part of Nigeria. Imo State covers an area of about 5100 square kilometer (sq. km) with a population density varying from $230-1400$ persons per sq. km and Orlu LGA occupies an area of 132.9 sq. km with a population density of about 1074 persons per sq. $\mathrm{km}$ [12]. The study centre is a 250 bed tertiary health care facility that offers undergraduate and postgraduate training and comprehensive inpatient and outpatient health care services.

\subsection{Study Population/Study Design}

The study population comprised, nursing mothers within the environment of Imo State University Teaching Hospital. The study design was a cross sectional analytical study. It involved enrolling all the nursing mothers present within IMSUTH during a 4 week study period (4th to 31 st October 2016) after informed consents were given.

\subsection{Inclusion/Exclusion Criteria}

Inclusion criteria; nursing mothers attending out-patient clinics including postnatal clinics, hospital staff members that are nursing mothers, nursing mothers visiting patients and nursing mothers on admission. Exclusion criteria: any nursing mother severely ill on admission.

\subsection{Data Collection and Analysis}

Data was collected using a pretested, structured self-administered questionnaire and for those who could not read, an interviewer administered questionnaire. 
The questionnaire was designed by the researchers and pretested in a hospital environment located in another LGA, outside the study area. The content validity was established and a reliability coefficient (alpha) of 0.78 was calculated. The questionnaire comprised 2 sections; section one: the socio-demographic characteristics; section two: breast feeding practices. Data was cleaned and validated manually, then analyzed using Software Package for Social Sciences (IBM-SPSS) version 22. Descriptive statistics (frequency tables and summary indices) were generated. Chi Square was used to test and determine significant associations between breastfeeding practice and sociodemographic characteristics. Binary logistic regression analysis was used to determine the sociodemographic predictors of exclusive breastfeeding practice. $\mathrm{P}$ value was set at 0.05 significant level.

\subsection{Ethical Considerations}

Ethical approval was obtained from the Ethics Committee of Imo State University Teaching Hospital Orlu. Informed consents were obtained from the participants. All authors hereby declare that the study has therefore been performed in accordance with the ethical standards laid down in the 1964 Declaration of Helsinki.

\section{Results}

Two hundred and five questionnaires were administered but 200 were completely and correctly filled with a response rate of $97.6 \%$.

\subsection{Sociodemographic Characteristics of Respondents}

Most of the respondents were married or cohabiting (96.0\%) and the majority were traders $(41.5 \%)$ within the ages of 26 - 35 years $(55.5 \%)$ with either a primary or secondary level of education (69.0\%) (Table 1).

Table 1. Sociodemographic characteristics.

\begin{tabular}{ccc}
\hline Variable & Category & Frequency $(\%) \mathrm{n}=200$ \\
\hline Maternal Age (Years) & $<26$ & $48(24.0)$ \\
Marital Status & $26-35$ & $111(55.5)$ \\
& $>35$ & $41(20.5)$ \\
& Single/Separated/Divorced/Widowed & $8(4.0)$ \\
Maternal Educational Level & Married/Cohabiting & $192(96.0)$ \\
& None & $30(15.0)$ \\
& Primary & $40(20.0)$ \\
& Secondary & $98(49.0)$ \\
& Tertiary & $32(16.0)$ \\
& Trader & $83(41.5)$ \\
Maternal Occupation & Housewife & $51(25.5)$ \\
& Civil servant & $30(15.0)$ \\
& Student & $29(14.5)$ \\
& Others & $7(3.5)$
\end{tabular}




\subsection{Breast Feeding Practices of Respondents}

Most of the respondents were aware of exclusive breast feeding (92.5\%) and the source of awareness for the majority, was from the health worker (45.9\%) (Table 2).

Only $24 \%$ of the respondents were practising exclusive breast feeding with the majority practising different forms of non-exclusive breastfeeding (76.0\%) (Figure 1).

Table 2. Breastfeeding practices.

\begin{tabular}{|c|c|c|}
\hline Variable & Category & Frequency $(\%)$ \\
\hline \multirow{2}{*}{$\begin{array}{l}\text { Aware of exclusive breastfeeding } \\
\qquad(\mathrm{n}=200)\end{array}$} & Yes & $185(92.5)$ \\
\hline & No & $15(7.5)$ \\
\hline \multirow{5}{*}{$\begin{array}{l}\text { Source of awareness of exclusive } \\
\text { breastfeeding }(\mathrm{n}=185)\end{array}$} & Health workers & $85(45.9)$ \\
\hline & Mass media & $38(20.5)$ \\
\hline & Church & $29(15.7)$ \\
\hline & Family & $28(15.2)$ \\
\hline & Books & $5(2.7)$ \\
\hline \multirow[t]{5}{*}{$\begin{array}{l}\text { Type of breastfeeding being practiced } \\
\qquad(\mathrm{n}=200)\end{array}$} & Breast milk alone for 6 months (exclusive) & $48(24.0)$ \\
\hline & Breast milk with water for 6 months & $60(30.0)$ \\
\hline & Breast milk with cereal for 3 months & $42(21.0)$ \\
\hline & Breast milk with infant formula for 6 months & $40(20.0)$ \\
\hline & Breast milk with cereal for 6 months & $10(5.0)$ \\
\hline \multirow{6}{*}{$\begin{array}{l}\text { Reasons for not practicing exclusive } \\
\text { breastfeeding }(\mathrm{n}=152)\end{array}$} & Work/School activities & $44(29.0)$ \\
\hline & Insufficient breast milk & $42(27.6)$ \\
\hline & Risk of breast sagging & $31(20.4)$ \\
\hline & Stressful & $23(15.1)$ \\
\hline & Others & $12(7.9)$ \\
\hline & $<10$ & $62(31.0)$ \\
\hline \multirow{4}{*}{$\begin{array}{l}\text { Age of child at which breastfeeding } \\
\text { would be completely stopped } \\
\text { (Months) }(\mathrm{n}=200)\end{array}$} & $10-14$ & $80(40.0)$ \\
\hline & $15-19$ & $36(18.0)$ \\
\hline & $20-24$ & $14(7.0)$ \\
\hline & $>24$ & $8(4.0)$ \\
\hline
\end{tabular}

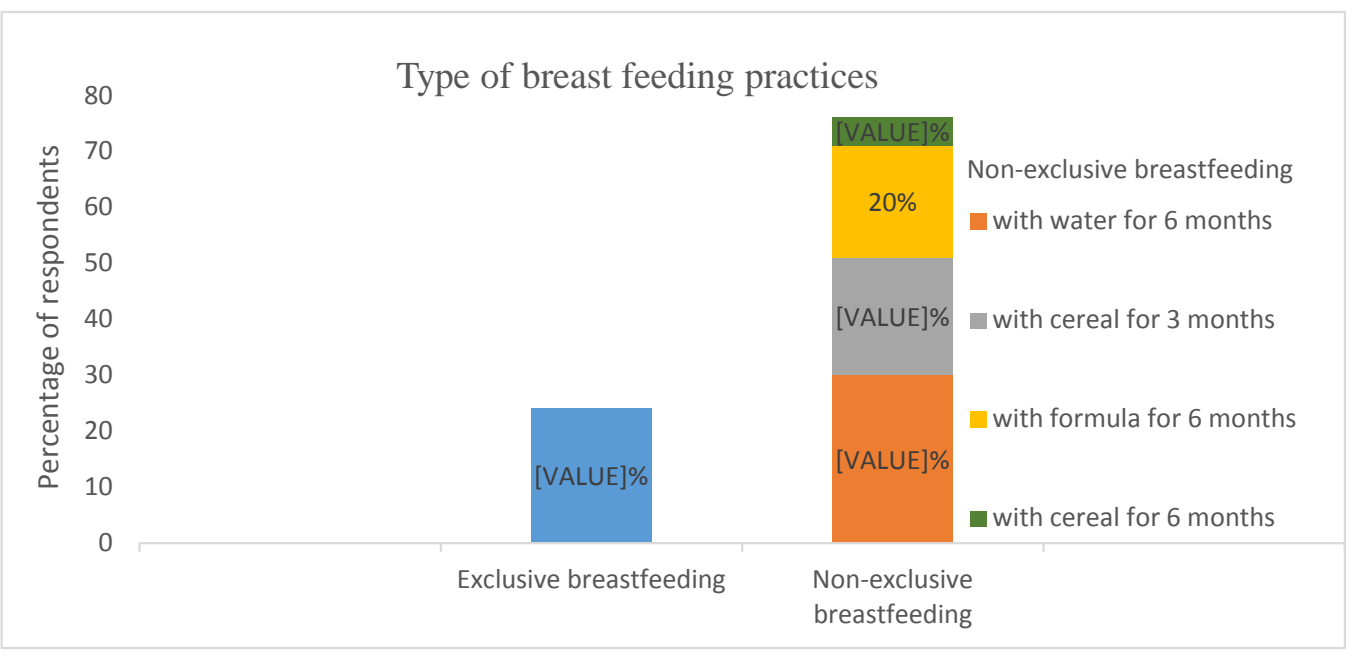

Figure 1. Breast feeding practices. 
The majority of those not practising exclusive breast feeding, attributed the reasons to work and school activities and also the feeling that breast milk was insufficient (56.6\%).

Also, the majority of the respondents $(40.0 \%)$ reported that they would completely stop breast feeding when the child is within the ages of $10-14$ months (Table 2).

\subsection{Sociodemographic Factors Associated with Breastfeeding Practices of respondents}

The following socio-demographic characteristics were significantly associated with breast feeding practices of the respondents; Maternal age $(p=0.003)$, Educational level $(p=0.005)$ and Occupation $(p=0.006)($ Table 3$)$.

\subsection{Sociodemographic Predictors for Exclusive Breastfeeding Practice of respondents}

The study respondents whose ages were above 35 years, were significantly more likely to practice exclusive breast feeding than those whose ages were less than 26 years [OR: 3.91; 95\% CI $(1.471-10.406) ; \mathrm{p}=0.005$ ]. Similarly, the respondents with a tertiary level of education when compared to those without an education were significantly more likely to practice exclusive breast feeding [OR: 7.94; $95 \%$ CI $(1.998$ - 31.571); $p=0.001]$. On the other hand, the following respondents were significantly less likely to practice exclusive breast feeding when compared to the housewife; traders [OR: 0.24; 95\% CI (0.109 - 0.551); $\mathrm{p}<0.000$ ] and students [OR: 0.27; 95\% CI (0.090 - 0.835); $\mathrm{p}=0.019$ ] (Table 4).

Table 3. Sociodemographic factors associated with breastfeeding practices.

\begin{tabular}{|c|c|c|c|c|c|c|}
\hline Variable & Exclusive (\%) & Non Exclusive (\%) & Total (\%) & $x^{2}$ & & $\mathrm{p}$-value \\
\hline \multicolumn{7}{|l|}{ Maternal Age (Years) } \\
\hline$<26$ & $8(16.7)$ & $40(83.3)$ & $48(100)$ & \multirow{4}{*}{11.38} & \multirow{4}{*}{2} & \multirow{4}{*}{$0.003^{*}$} \\
\hline $26-35$ & $22(19.8)$ & $89(80.2)$ & $111(100)$ & & & \\
\hline$>35$ & $18(43.9)$ & $23(56.1)$ & $41(100)$ & & & \\
\hline Total & $48(24.0)$ & $152(76.0)$ & $200(100)$ & & & \\
\hline \multicolumn{7}{|l|}{ Marital Status } \\
\hline Single $^{\mathrm{a}}$ & $1(12.5)$ & $7(87.5)$ & $8(100)$ & \multirow{3}{*}{0.60} & \multirow{3}{*}{1} & \multirow{3}{*}{0.437} \\
\hline Married/Cohabiting & $47(24.5)$ & $145(75.5)$ & $192(100)$ & & & \\
\hline Total & $48(24.0)$ & $152(76.0)$ & $200(100)$ & & & \\
\hline \multicolumn{7}{|l|}{ Educational Level } \\
\hline None & $3(10.0)$ & $27(90.0)$ & $30(100)$ & \multirow{5}{*}{12.88} & \multirow{5}{*}{3} & \multirow{5}{*}{$0.005^{*}$} \\
\hline Primary & $8(20.0)$ & $32(80.0)$ & $40(100)$ & & & \\
\hline Secondary & $22(22.4)$ & $76(77.6)$ & $98(100)$ & & & \\
\hline Tertiary & $15(46.9)$ & $17(53.1)$ & $32(100)$ & & & \\
\hline Total & $48(24.0)$ & $152(76.0)$ & $200(100)$ & & & \\
\hline \multicolumn{7}{|l|}{ Occupation } \\
\hline Civil servants & $7(23.3)$ & $23(76.7)$ & $30(100)$ & \multirow{6}{*}{14.50} & \multirow{6}{*}{4} & \multirow{6}{*}{$0.006^{*}$} \\
\hline Housewife & $22(43.1)$ & $29(56.9)$ & $51(100)$ & & & \\
\hline Trader & $13(15.7)$ & $70(84.3)$ & $83(100)$ & & & \\
\hline Student & $5(17.2)$ & $24(82.8)$ & $29(100)$ & & & \\
\hline Others & $1(14.3)$ & $6(85.7)$ & $7(100)$ & & & \\
\hline Total & $48(24.0)$ & $152(76.0)$ & $200(100)$ & & & \\
\hline
\end{tabular}

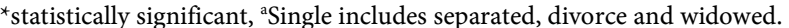


Table 4. Sociodemographic predictors for exclusive breast feeding practice.

\begin{tabular}{cccc}
\hline Variable & OR (estimate) & $95 \%(\mathrm{CI})$ & p-value \\
\hline Maternal Age (Years) & & & \\
$<26$ & 1.00 & --- & - \\
$26-35$ & 1.24 & $0.507-3.013$ & 0.639 \\
$>35$ & 3.91 & $1.471-10.406$ & $0.005^{*}$ \\
Educational Level & & & \\
None & 1.00 & --- & -- \\
Primary & 2.25 & $0.543-9.330$ & 0.331 \\
Secondary & 2.61 & $0.722-9.405$ & 0.133 \\
Tertiary & 7.94 & $1.998-31.571$ & $0.001^{*}$ \\
Occupation & & & \\
Housewife & 1.00 & -- & - \\
Civil servants & 0.40 & $0.146-1.103$ & 0.073 \\
Trader & 0.24 & $0.109-0.551$ & $\mathbf{0 . 0 0 0}$ \\
Student & 0.27 & $0.090-0.835$ & $\mathbf{0 . 0 1 9 *}$ \\
Others & 0.22 & $0.025-1.960$ & 0.226 \\
\hline
\end{tabular}

\section{Discussion}

This study assessed the breast feeding practices and its associated sociodemographic determinants of nursing mothers at a tertiary care hospital and it revealed that only $24 \%$ of the respondents were practicing exclusive breast feeding; and that, the following sociodemographic factors; maternal age, level of education and occupation were significantly associated with the practice of breast feeding.

This low level of exclusive breast feeding practice among nursing mothers in Nigeria as observed in the present study, though also established in a number of other Nigerian studies, the prevalence of exclusive breastfeeding appear to vary across and within the regions from $10 \%-56 \%$ [13]-[19], with a few studies reporting prevalence rates above 50\% [18] [19]. This varying levels of prevalence rates observed, may not only be due to the differing methodologies and exclusive breast feeding definitions adopted by these studies, but to existing risk factors such as socio-demographics, customs, attitudes, beliefs and women's work conditions.

In the present study, even though the majority of the nursing mothers were aware of exclusive breastfeeding (92.5\%), it appeared not to have influenced its practice. This level of practice observed, could probably be due to other overriding factors such maternal age, occupation and level of education, as the majority of the study participants were 35 years or less and were either traders, civil servants or students with a primary or secondary level of education.

Also, it was not unusual in this study group that, the majority of the respondents' source of awareness of exclusive breastfeeding was from the health worker followed by the mass media and the least from books. This may be due to the higher probability of contact, women of reproductive age generally have with the 
health institutions either through antenatal care visits, birth delivery, post-natal care and child immunization visits; and also, the increase in engaging social media. This observation was similar with studies done in communities in the South East and South-South regions of Nigeria, where the major source of their breastfeeding knowledge was from the health facility or health worker [16] [20].

In the present study, non-exclusive breast feeding was predominant with the majority of them giving water in addition to breast milk for 6 months. This could be due to the mothers' lack of proper understanding of what exclusive breast feeding means, though a Nigerian study in a rural community in the South-West region reported that the mothers felt that the babies need water to "quench their thirst" [13].

In the present study, the majority of the respondent's reasons for not practicing exclusive breastfeeding were work-school activities and the feeling that breast milk was insufficient for the needs of the baby. This could probably explain why up to $61 \%$ of the respondents that were practicing non-exclusive breast feeding gave a cereal or infant formula in addition to the breast milk for 3 6 months. The issue of work as a reason for not practising exclusive breastfeeding and the feeling that breast milk is insufficient has also been reported in a number of other Nigerian studies [13] [14] [19].

In the present study, majority of the respondents reported that they would completely stop breastfeeding when the child is between 10 - 14 months with a decreasing proportion of respondents reporting that, they would completely stop as the child reaches 24 months or more. On the contrary, a study by Oche et al. [15], though the sample size was relatively small, reported that most of their study participants, stopped breastfeeding when the child was between the ages of 16 - 20 months.

Furthermore, a systematic review of breastfeeding in Nigeria over a 35 year period, reported an increasing trend in the mean duration of breastfeeding from 10 months in 1979 to 13 months in 2014 with varying periods of duration across and within the regions [21]. In spite of this, it appears that, the mean duration of breastfeeding practice in Nigeria is relatively stable and less than optimum; and as such, does not conform with the WHO's recommendation of continued breastfeeding up to 2 years of age or beyond [1] [3]. This may be attributed but not limited to the cultural diversity in Nigeria with respect to customs, traditions and beliefs; in order words, the role of multifactorial determinants in the practice of breast feeding in Nigeria.

In the present study, maternal age was significantly associated with the practice of breastfeeding. It was observed that nursing mothers above 35 years when compared to those less than 26 years, were significantly more likely to practice exclusive breast feeding. This is probably due to the experiences of older women with respect to the observed benefits and also, the recurring and reinforcing information heard about the benefits of exclusive breastfeeding from health facilities, social media and other sources over time. This was similarly observed in other studies that either reported an association with older maternal age or an 
increasing exclusive breastfeeding rate among nursing mothers with increasing maternal age [16] [20] [22] [23] [24]. On the contrary, it was inconsistent with a study in Ethiopia [25] that reported no association of exclusive breastfeeding with maternal age.

Also, in the present study, maternal educational level was significantly associated with practice of breastfeeding. It was observed that nursing mothers with a tertiary level of education when compared to those without an education were significantly more likely to practice exclusive breast feeding. This is probably due to the fact that, they are better able to comprehend the benefits and consequences within the context of existing customs, traditions, social and environmental constraints. This association of exclusive breastfeeding with the level of maternal educational has also been observed consistently in various studies [18] [19] [20] [22]-[27].

Furthermore, in the present study, maternal occupation was significantly associated with practice of breastfeeding. It was observed that nursing mothers who were housewives when compared to either traders or students were significantly more likely to practice exclusive breastfeeding. This probably, may be due to the fact that housewives appear to have more control over their time and as such, are able to practice exclusive breastfeeding on demand. Hence, without work or school constraints, they are able to provide breast milk as often as the child wants at any time of the day or night. In support of this, studies by Asma et al. [22] and Seid et al. [26] observed a decreased exclusive breastfeeding rate among working mothers and an association of exclusive breastfeeding with nursing mothers that were housewives respectively. On the contrary, Alemayehu et al. [25] reported no association of exclusive breastfeeding with maternal employment.

\section{Conclusion}

High level of awareness of exclusive breastfeeding alone, does not necessarily translate to the practice of exclusive breastfeeding, as there appears to be an interplay of multiple factors which also includes non-modifiable factors such as the sociodemographic factors. Hence, it is important to understand and take into cognisance the sociodemographic characteristics that influence the likelihood of nursing mothers practising exclusive breastfeeding. This will enable the design and adequate delivery of appropriate and effective strategies that actively support the establishment and sustenance of exclusive breastfeeding practice.

\section{Acknowledgements}

We thank all the participants in this study and the research assistants who helped during the data collection.

\section{Authors' Contributions}

All authors participated in the study. 


\section{Conflict of Interest}

The authors hereby declare that there is no conflict of interests.

\section{Source of Funding}

There was no external source of funding for the research work.

\section{References}

[1] World Health Organization (WHO) (2017) Nutrition; Exclusive Breastfeeding. http://www.who.int/nutrition/topics/exclusive_breastfeeding/en/

[2] Kramer, M.S. and Kakuma, R. (2009) Optimal Duration of Exclusive Breastfeeding (Systematic Review). The Cochrane Library, 4.

[3] World Health Organization (WHO) (2017) Nutrition; Promoting Proper Feeding for Infants and Young Children. http://www.who.int/nutrition/topics/infantfeeding/en/

[4] United Nations Working Group on Discrimination against Women in Law and in Practice, and the UN Committee on the Rights of the Child (UN Special Rapporteurs) (2016) The Joint Statement on the Right to Food and the Right to Health. http://www.who.int/nutrition/topics/UNhumanrights-statement-breastfeeding-righ $\underline{\text { ts/en/ }}$

[5] World Health Organization (WHO) (2016) Infant and Young Child Feeding Fact Sheet. http://www.who.int/mediacentre/factsheets/fs342/en/

[6] World Health Organization (WHO) (2012) World Breastfeeding Week-2012-Pledge Now: 20 Years World Breastfeeding Week Partnership for Maternal, Newborn \& Child Health.

http://www.who.int/pmnch/media/news/2012/2012_world_breastfeeding_week/en/ index1.html

[7] National Population Commission (NPC) (Nigeria) and ICF International (2014) Nigeria Demographic and Health Survey 2013. NPC and ICF International, Abuja and Rockville.

[8] Victora, C.G., Bahl, R., Barros, J.D., Franca, V.A., Horton, S., Krasevec, J., et al. (2016) Breastfeeding in the 21st Century: Epidemiology, Mechanisms, and Lifelong Effect. The Lancet, 387, 475-490.

[9] Edmond, K., Zandoh, C., Quigley, M. A., Amenga-Etego, S., Owusu-Agyei, S. and Kirkwood, B. (2006) Delayed Breastfeeding Initiation Increases Risk of Neonatal Mortality. Pediatrics, 117, E380-E386. https://doi.org/10.1542/peds.2005-1496

[10] Jones, G., Steketee, R.W., Black, R.E., Bhutta, Z.A. and Morris, S.S. (2003) How Many Child Deaths Can We Prevent This Year? The Lancet, 362, 65-71.

[11] Rollins, N.C., Bhandari, N., Hajeebhoy, N., Horton, S., Lutter, C.K., Martines, J.C., et al. (2016) Why Invest, and What It Will Take to Improve Breastfeeding Practices? The Lancet, 387, 491-504.

[12] National Population Commission and Federal Republic of Nigeria (2006) Population and Housing Census: Priority-Table-Volume III. http://www.population.gov.ng/index.php/censuses

[13] Alade, O., Titiloye, M.A., Oshiname, F.O. and Arulogun, O.S. (2013) Exclusive Breastfeeding and Related Antecedent Factors among Lactating Mothers in a Rural Community in Southwest Nigeria. International Journal of Nursing and Midwifery, $5,132-138$.

[14] Agunbiade, O.M. and Ogunleye, O.V. (2012) Constraints to Exclusive Breastfeeding 
Practice among Breastfeeding Mothers in Southwest Nigeria: Implications for Scaling Up. International Breastfeeding Journal, 7, 5.

https://doi.org/10.1186/1746-4358-7-5

[15] Oche, M., Umar, A. and Ahmed, H. (2011) Knowledge and Practice of Exclusive Breastfeeding in Kware, Nigeria. African Health Sciences, 11, 518-523.

[16] Ukegbu, A.U., Ebenebe, E.U., Ukegbu, P.O. and Onyeonoro, U.U. (2011) Determinants of Breastfeeding Pattern among Nursing Mothers in Anambra State, Nigeria. East African Journal of Public Health, 8, 226-231.

[17] Ugboaja, J.O., Berthrand, N.O., Igwegbe, A.O. and OBI-Nwosu, A.L. (2013) Barriers to Postnatal Care and Exclusive Breastfeeding among Urban Women in South Eastern Nigeria. Nigerian Medical Journal, 54, 45-50.

https://doi.org/10.4103/0300-1652.108895

[18] Okafor, I.P., Olatona, F.A. and Olufemi, O.A. (2014) Breastfeeding Practices of Mothers of Young Children in Lagos, Nigeria. Nigerian Journal of Paediatrics, 41, 43-47.

[19] Sholeye, O.O., Abosede, O.A. and Salako, A.A. (2015) Exclusive Breastfeeding and Its Associated Factors among Mothers in Sagamu, Southwest Nigeria. Journal of Health Science, 5, 25-31.

[20] Peterside, O., Kunle-olowu, O.E. and Duru, C. (2013) Knowledge and Practice of Exclusive Breastfeeding among Mothers in Gbarantoru Community, Bayelsa State, Nigeria. IOSR Journal of Dental and Medical Sciences, 12, 34-40. https://doi.org/10.9790/0853-1263440

[21] Adewuyi, E.O. and Adefemi, K. (2016) Breastfeeding in Nigeria: A Systematic Review. International Journal of Community Medicine and Public Health, 3, 385-396. https://doi.org/10.18203/2394-6040.ijcmph20160421

[22] Asma, M.Q., Oche, M.O., Umar, A.S. and Sabitu, K. (2011) Using Community Volunteers to Promote Exclusive Breastfeeding in Sokoto State, Nigeria. Pan African Medical Journal, 10, 8.

[23] Ogbo, F.A., Agho, K.E. and Page, A. (2015) Determinants of Suboptimal Breastfeeding Practices in Nigeria: Evidence from the 2008 Demographic and Health Survey. BMC Public Health, 15, 259. https://doi.org/10.1186/s12889-015-1595-7

[24] Gayawan, E., Adebayo, S.B. and Chitekwe, S. (2014) Exclusive Breastfeeding Practice in Nigeria: A Bayesian Stepwise Regression Analysis. Maternal and Child Health Journal, 18, 2148-2157. https://doi.org/10.1007/s10995-014-1463-6

[25] Alemayehu, T., Haidar, J. and Habte, D. (2009) Determinants of Exclusive Breast Feeding Practice in Ethiopia. Ethiopian Journal of Health Development, 23, 13-18. https://doi.org/10.4314/ejhd.v23i1.44832

[26] Seid, A.M., Yesuf, M.E. and Koye, D.N. (2013) Prevalence of Exclusive Breastfeeding Practices and Associated Factors among Mothers in Bahir Dar City, Northwest Ethiopia: A Community Based Cross-Sectional Study. International Breastfeeding Journal, 8, 14. https://doi.org/10.1186/1746-4358-8-14

[27] Onah, S., Osuorah, D.I., Ebenebe, J., Ezechukwu, C., Ekwochi, U. and Ndukwu, I. (2014) Infant Feeding Practices and Maternal Socio-Demographic Factors That Influence Practice of Exclusive Breastfeeding among Mothers in Nnewi South-East Nigeria: A Cross-Sectional and Analytical Study. International Breastfeeding Journal, 9, 6. https://doi.org/10.1186/1746-4358-9-6 
Submit or recommend next manuscript to SCIRP and we will provide best service for you:

Accepting pre-submission inquiries through Email, Facebook, LinkedIn, Twitter, etc. A wide selection of journals (inclusive of 9 subjects, more than 200 journals)

Providing 24-hour high-quality service

User-friendly online submission system

Fair and swift peer-review system

Efficient typesetting and proofreading procedure

Display of the result of downloads and visits, as well as the number of cited articles Maximum dissemination of your research work

Submit your manuscript at: http://papersubmission.scirp.org/

Or contact ojpm@scirp.org 